\title{
The Role of Epigenetic Regulation in Epstein-Barr Virus-Associated Gastric Cancer
}

\author{
Jun Nishikawa ${ }^{1, *}$, Hisashi Iizasa ${ }^{2}$, Hironori Yoshiyama ${ }^{2}$ (D), Munetaka Nakamura ${ }^{3}$, \\ Mari Saito ${ }^{3}$, Sho Sasaki ${ }^{3}$, Kanami Shimokuri ${ }^{1}$, Masashi Yanagihara ${ }^{1}$, Kouhei Sakai ${ }^{4}$, \\ Yutaka Suehiro ${ }^{4}$, Takahiro Yamasaki ${ }^{4}$ and Isao Sakaida ${ }^{3}$ \\ 1 Department of Laboratory Science, Yamaguchi University Graduate School of Medicine, Ube, \\ Yamaguchi 755-8505, Japan; g006up@yamaguchi-u.ac.jp (Ka.S.); m-yanagi@yamaguchi-u.ac.jp (M.Y.) \\ 2 Department of Microbiology, Shimane University Faculty of Medicine, 89-1 Enyacho, Izumo City, \\ Shimane 693-8501, Japan; iizasah@med.shimane-u.ac.jp (H.I.); yosiyama@med.shimane-u.ac.jp (H.Y.) \\ 3 Department of Gastroenterology and Hepatology, Yamaguchi University Graduate School of Medicine, Ube, \\ Yamaguchi 755-8505, Japan; munemune84@hotmail.com (M.N.); mari-s@zj8.so-net.ne.jp (M.S.); \\ u003uj@yamaguchi-u.ac.jp (S.S.); sakaida@yamaguchi-u.ac.jp (I.S.) \\ 4 Department of Oncology and Laboratory Medicine, Yamaguchi University Graduate School of Medicine, \\ Ube, Yamaguchi 755-8505, Japan; sakaik@yamaguchi-u.ac.jp (Ko.S.); ysuehiro@yamaguchi-u.ac.jp (Y.S.); \\ t.yama@yamaguchi-u.ac.jp (T.Y.) \\ * Correspondence: junnis@yamaguchi-u.ac.jp; Tel./Fax: +81-836-22-2361
}

Received: 6 July 2017; Accepted: 22 July 2017; Published: 25 July 2017

\begin{abstract}
The Epstein-Barr virus (EBV) is detected in about 10\% of gastric carcinoma cases throughout the world. In EBV-associated gastric carcinoma (EBVaGC), all tumor cells harbor the clonal EBV genome. The expression of latent EBV genes is strictly regulated through the methylation of EBV DNA. The methylation of viral DNA regulates the type of EBV latency, and methylation of the tumor suppressor genes is a key abnormality in EBVaGC. The methylation frequencies of several tumor suppressor genes and cell adhesion molecules are significantly higher in EBVaGC than in control cases. EBV-derived microRNAs repress translation from viral and host mRNAs. EBV regulates the expression of non-coding RNA in gastric carcinoma. With regard to the clinical application of demethylating agents against EBVaGC, we investigated the effects of decitabine against the EBVaGC cell lines. Decitabine inhibited the cell growth of EBVaGC cells. The promoter regions of p73 and Runt-related transcription factor 3(RUNX3) were demethylated, and their expression was upregulated by the treatment. We review the role of epigenetic regulation in the development and maintenance of EBVaGC and discuss the therapeutic application of DNA demethylating agents for EBVaGC.
\end{abstract}

Keywords: epigenetics; epstein-barr virus; gastric cancer; DNA methylation; microRNA; non-coding RNA; demethylating agent

\section{Introduction}

Gastric cancer is the third leading cause of cancer-related mortality and is responsible for approximately 450,000 deaths worldwide each year [1,2]. Since gastric cancer has a heterogeneous etiology and histopathology [3], the optimum chemotherapy regimen for advanced cases-according to the molecular biological understanding of gastric cancer-has not been established.

The Epstein-Barr virus (EBV) is a double-stranded DNA virus belonging to the herpes virus family, which latently infects B lymphocytes in the majority of adults. EBV is closely associated with both lymphoid and epithelial malignancies, such as Burkitt lymphoma and nasopharyngeal carcinoma [4]. The existence of the EBV genome in gastric cancer was first detected using a polymerase chain reaction in 1990 [5]. Since then, approximately $10 \%$ of gastric cancers in the world have been 
identified as positive for EBV [6]. In situ hybridization for EBV-encoded small RNA 1 (EBER1) has been used as the standard method for diagnosing EBV-positive gastric cancer. EBER1 signals can be detected in the nuclei of gastric cancer cells (Figure 1) [7,8]. Imai et al. [9] reported that EBV-associated gastric carcinoma (EBVaGC) resulted from the monoclonal proliferation of EBV-infected cells. This fact suggests that EBV plays an important role in the development of cancer [10].

Recently, the Cancer Genome Atlas (TCGA) of gastric adenocarcinomas [11] developed a novel classification system dividing gastric cancer into four molecular groups: (1) EBVaGC; (2) microsatellite instability (MSI); (3) chromosomal instability (CIN); and (4) genomically stable (GS) tumors. The characteristics of EBVaGC are reported to include the harboring of recurrent PIK3CA mutations, extreme DNA hypermethylation, and amplification of JAK2, PD-L1, and PD-L2. PIK3CA mutation and amplification of JAK2 could lead to PD-L1 overexpression [11]. Recently, many reports have addressed PD-L1 overexpression in EBVaGC [12-14]. It is possible that EBVaGC tumor cells evade immune reactions via the PD-1/PD-L1 immune check point pathway. Among these characteristics of EBVaGC, promoter hypermethylation and the downregulation of various tumor suppressor genes have already been reported [15-19].

In the present study, we review the role of DNA methylation in the development and maintenance of EBVaGC and discuss the therapeutic application of DNA demethylating agents for EBVaGC.

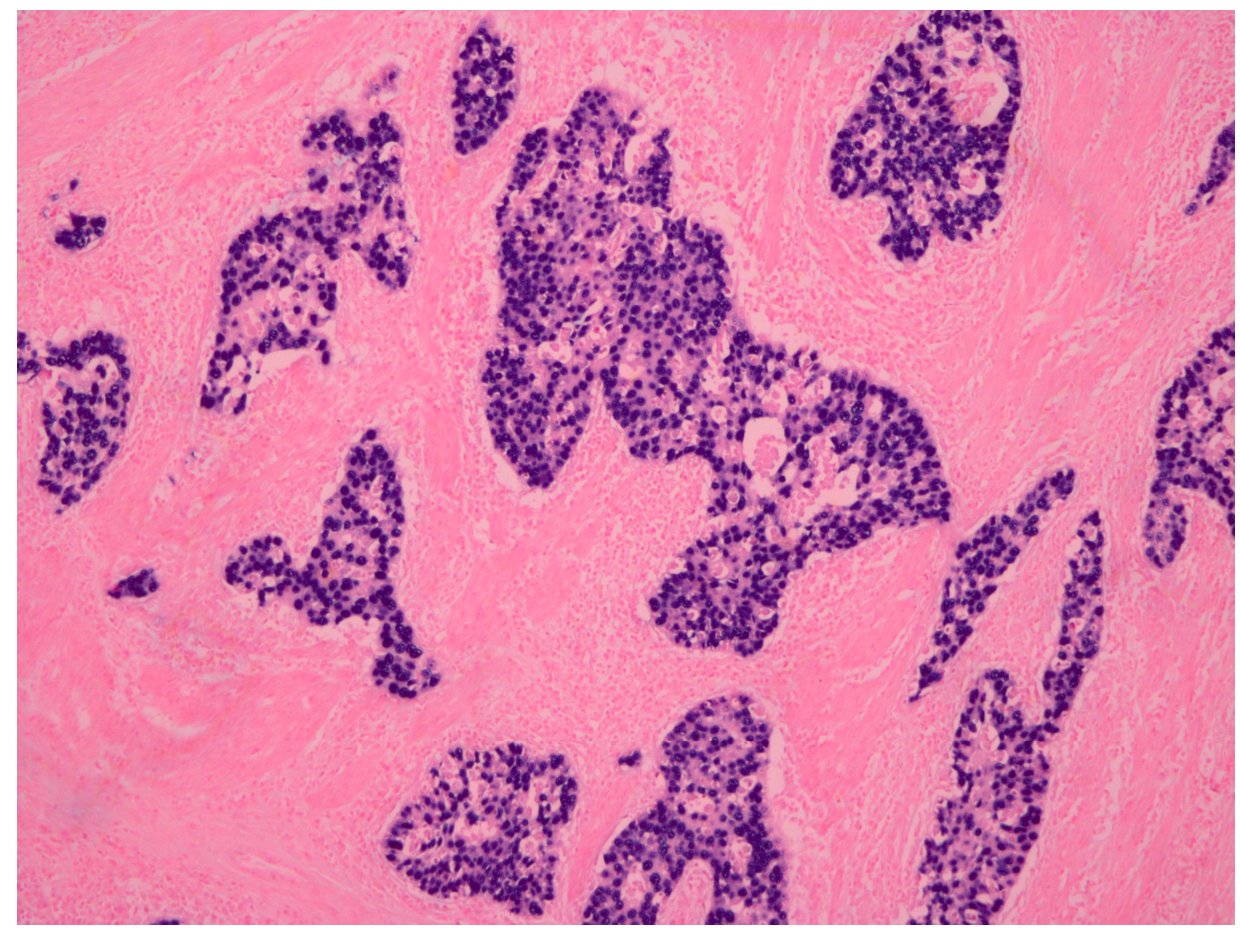

Figure 1. Representative case of Epstein-Barr virus (EBV)-associated gastric carcinoma. EBV-encoded small RNA 1 (EBER1) in situ hybridization $(\times 100)$. Signals of EBER1 were detected in the nucleus of almost all cancer cells.

\section{The Epigenetic Regulation of Latent Epstein-Barr Virus (EBV) Gene Expression}

DNA methylation of the EBV genome has been studied intensively in EBV-associated tumors. It has been revealed that the expression of latent EBV genes is regulated by methylation in their promoter regions [20]. EBV-associated tumors exhibit three patterns of latency: types I, II, and III. Tumors with type I latency only express the EBV nuclear antigen (EBNA) 1 protein, as observed in Burkitt lymphoma. Tumors with type II latency express EBNA1, latent membrane protein (LMP) 1, and LMP2, as observed in EBV carrying T/NK cell lymphomas, nasopharyngeal carcinomas (NPC), and Hodgkin's lymphoma. Tumors with type III latency express EBNA1-6 and LMP1 and 
LMP2s, as observed in immunoblastic lymphocytes arising in immunocompromised patients (Table 1). Similarly to Burkitt lymphoma, EBVaGCs are considered to show type I latency [9]. A limited set of viral genes, including EBNA1, EBERs, and Bam HI-A transcripts (BARTs), are expressed in neoplasms showing type I latency. EBNA promoters ( $\mathrm{Cp}$ and $\mathrm{Wp}$ ), which can transcribe all EBNAs, are hypermethylated in tumors showing type I latency, and the alternative EBNA promoter Qp is used [21,22]. These results indicate that the methylation status of the EBV genome regulates the pattern of latent gene expression in EBV-positive tumor cells.

Table 1. The pattern of Epstein Barr virus (EBV) latent gene expression and promoter usage.

\begin{tabular}{ccccccc}
\hline \multirow{2}{*}{ Type of Latency } & \multirow{2}{*}{ Latent Gene Expression } & \multicolumn{2}{c}{ Promoter Hypermethylation } & \multirow{2}{*}{ EBV-Associated Diseases } \\
\cline { 3 - 5 } & & E $/ \mathbf{W p}$ & Qp & LMP1p & \\
\hline Type I & EBNA1 & + & - & + & Burkitt lymphoma; Gastric cancer \\
\hline Type II & EBNA1, LMP2 & + & - & $+/-$ & $\begin{array}{c}\text { Nasopharyngeal cancer, Hodgikin } \\
\text { disease, NK/T cell lymphoma }\end{array}$ \\
\hline Type III & EBN1, LMP2 & - & - & - & Immunosuppressive lymphoma \\
\hline
\end{tabular}

EBV, Epstein-Barr virus; EBNA, Epstein-Barr Virus nuclear antigen; LMP1, Latent membrane protein 1; Cp, C promoter; $\mathrm{Wp}, \mathrm{W}$ promoter.

There are reports that LMP2A mRNA was detected in some EBVaGCs [23,24]. EBV lytic genes, including BCLF1, BHRF1, BNLF2a, and BRLF1, were also expressed in EBVaGC [25]. Especially, BNLF2a is expressed in latently-infected tumor cells [26]. A systemic review by Ribeiro et al. showed that the most frequently expressed EBV latent proteins are EBNA1 (98.1\%) and LMP2A (53.8\%), whereas LMP1 and LMP2B are present in only $10 \%$ of cases. Lytic proteins, such as BARF0 and BARF1, and other lytic transcripts are present in almost half of the cases [27]. The pattern of latent EBV infection is more complex than the type I latency pattern (EBNA1, EBERs) initially described.

Latent membrane protein 1 (LMP1) is a latent EBV gene that shows oncogenic activity and which is recognized and targeted by cytotoxic T lymphocytes. Approximately $60 \%$ of NPC cells carrying EBV express LMP1, while the frequency of LMP1 expressing cells in tumor tissue displays a high degree of variability. In these tumors, the expression of LMP1 is controlled by the methylation status of the LMP1 promoter (LMP1p). LMP1 is expressed in tumor cells that possess an EBV genome with an unmethylated LMP1p, not in tumor cells that possess an EBV genome with a highly methylated LMP1p [28]. The downregulation of LMP1 is also observed in EBVaGC. LMP1 promoter is hypermethylated in the EBV genome of EBVaGC tumors. DNA methylation is utilized as a host defense mechanism against viral DNA to suppress the expression of viral genes [29,30]. On the other hand, DNA methylation plays a crucial role in allowing EBV to escape from the surveillance of the host immune system.

The expression of latent EBV genes is strictly regulated through the methylation of EBV DNA. The methylation of viral DNA determines the type of EBV latency, which may contribute to the maintenance of EBVaGC.

\section{DNA Hypermethylation in the Host Genome}

The methylation of tumor suppressor genes is a key abnormality in EBVaGC. In the tumor cells of EBVaGC, CpG island methylation is frequently observed at promoters of various tumor-related genes, which plays important roles in the development and progression of gastric cancer [12,13]. The methylation frequencies of several tumor suppressor genes (i.e., APC, PTEN, and RASSF1A) and cell adhesion molecules (i.e., THBS1 and E-cadherin) are significantly higher in EBVaGC compared to EBV-negative controls [31-33]. Hypermethylation of somatostatin receptor 1, interferon regulatory factor 5, REC8 meiotic recombination protein, SLIT1, SLIT2, and SLIT3 was recently reported, and the methylation frequency was significantly higher in EBVaGC than in EBV-negative gastric cancer [34-36]. 
We compared the methylation status between EBVaGC and EBV-negative gastric cancer in patients matched for age, sex, histology, depth of invasion, and tumor stage. The methylation frequency in 12 of 16 tumor-related genes was significantly higher in EBVaGC than in EBV-negative gastric cancer by methylation-specific PCR (MSP). The methylation frequencies at six specific loci (MINT2, MINT31, p14, p16, p73, and Runt-related transcription factor 3(RUNX3)) in EBVaGC were significantly higher in comparison to EBV-negative gastric cancer [19]. The DNA methylation status was also examined in SNU-719 cells, which were derived from EBV-positive gastric adenocarcinoma, by the method of methylated $\mathrm{CpG}$ island recovery in a chip assay. We demonstrated that the promoter regions of p73, BLU, FSD1, BCL7A, MARK1, SCRN1, and NKX3.1 were methylated and their expression was upregulated by a demethylating agent. Their methylation frequencies in EBVaGC were significantly higher in comparison to EBV-negative gastric cancer [18].

The mechanism that induces cellular DNA methylation by EBV infection of the gastric epithelium is not fully understood. LMP2A can activate the transcription of DNA methyltransferase 1 (DNMT1) through the phosphorylation of STAT3 [37]. However, LMP2A is not expressed in all cases of EBVaGC [24], and EBVaGC patients are usually negative for LMP2A antibodies [38]. LMP1 can also induce aberrant DNA methylation by activating DNMT1 through the JNK signaling pathway [39] and by inducing DNA methylation in the host cells [40]. However, LMP1 is scarcely expressed, and the LMP1 protein is usually not expressed in EBVaGC [41]. Matsusaka et al. showed that when EBV was introduced into the EBV-negative/low-methylation epigenotype gastric cancer cell MKN7, DNA methylation was induced in the cells [42]. They recently described the observation of similar DNA methylation in non-neoplastic gastric epithelial cell line GES1 after EBV infection [43]. They concluded that DNA methylation could be attributed to EBV infection.

Methylation of both viral and host DNA is one of the major mechanisms involved in the development of EBVaGC. DNA methylation could be induced by EBV infection in epithelial cells. Viral DNA methylation inhibits the expression of EBV latent genes. Methylation of host cell DNA-inactivated tumor suppressor genes and tumor associated antigens (Figure 2).

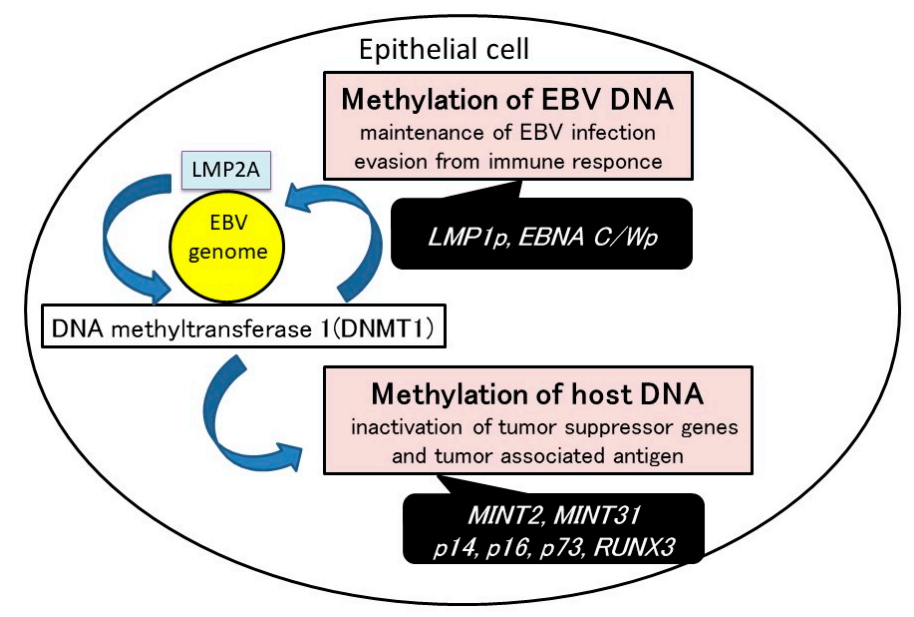

Figure 2. The mechanism of EBV-induced gastric carcinogenesis. DNA methylation can be induced by EBV infection in epithelial cells. Methylation of both viral and host DNA is one of the major mechanisms involved in the development of EBV-associated gastric carcinoma (EBVaGC). Viral DNA methylation regulates EBV latency type and inhibits the expression of EBV latent genes that are possible targets of cytotoxic T lymphocytes. Methylation of host cell DNA might lead to the progression of EBVaGC. The inactivation of cellular genes through DNA methylation might contribute to cell-cycle dysregulation and anti-apoptotic effects in EBVaGC. 


\section{MicroRNA (miRNA)}

miRNA consists of 21-25-bp non-coding RNA and is generated from primary miRNAs (pri-miRNAs) through a multi-step process. In the nucleus, pri-miRNAs are transcribed by RNA polymerase II as incomplete double-stranded RNAs and cleaved by the Drosha-DGCR8 complex to generate intermediate miRNA (precursor miRNA [pre-miRNA]). Pre-miRNAs are transported from the nucleus to the cytoplasm by Exportin5-RanGTP8 complex and are processed by the Dicer-TRBP2 complex to create mature miRNAs. miRNAs are captured by RNA-induced silencing complex (RISC). RISC binds to the 3'UTR of mRNA; RISC-miRNA suppresses translation and induces deadenylation to enhance mRNA degradation [44]. A total of 2588 miRNAs have been identified in Homo sapiens, and it is estimated that $30-50 \%$ of genes are regulated by miRNAs [45].

\subsection{EBV Encoded miRNAs}

In 2004, Pfeffer et al. reported that EBV B95-8 strain has pri-miRNA-like structures and that viral miRNAs are produced using host enzymes [46]. Thereafter, it was found that many viral miRNAs were present in the BART intron region, which was lacking in the B95-8 strain. It has since been confirmed that EBV has 44 miRNAs (miR-BHRF1s, miR-BARTs: Table 2 and Figure 3) [47]. miR-BARTs are highly expressed in NPC and EBVaGC in comparison to EBV-positive B lymphoma [48]. In contrast, miR-BHRF1s are expressed in LCL, but not in Burkitt lymphoma, NPC, or EBVaGC [48]. EBV is expressed in a limited number of genes in EBVaGC. Thus, it was important to clarify the function of miR-BARTs in EBVaGC. miR-BART20-5p was found to target apoptosis-inducing factor, Bcl2-associated agonist of cell death $(B A D)$ and induce the proliferation of gastric cancer cells by repressing the expression of BAD [49]. Moreover, miR-BART4-5p was found to target BH3 interacting domain death agonist (BID), which is a Bcl-2 family gene, and suppress apoptosis in gastric cancer cells [50]. In addition to targeting $B A D$ and $B I D$, miR-BARTs were shown to suppress cell death by targeting various apoptosis-related genes [51].

The mRNA profiles of epithelial cells and B cells are different, and it is hypothesized that the target genes of miR-BARTs also depend on the cell type. Kanda et al. reported that multiple miR-BARTs, including miR-BART22, targeted the epithelial cell differentiation marker NDRG1 [52]. This is an essential gene for maintaining epithelial cell differentiation. The effect of miR-BARTs is not limited to EBV-infected cells because miRNAs are secreted extracellularly by exosomes [21]. miR-BART11 is reported to cause the dedifferentiation of epithelial cells and tumor-infiltrating macrophages by targeting the cell differentiation-inducing factor Forkhead Box P1 (FOXP1) [53].

In cases of EBVaGC involving latent EBV infection, the viral antigens are expressed at very low levels, allowing the virus to escape the immune system and a state of persistent infection to be maintained. miR-BART6 was shown to induce latent EBV infection [54]. In addition, miR-BART20-5p was shown to target lytic infection, inducing factors BZLF1 and BRLF1, and to induce latent viral infection [55]. Although the expression of BZLF1 was shown to be enhanced in a miR-BART-deleted EBV strain, it was found that the strain progressed to a lytic condition more easily in comparison to a wild-type strain [56].

BART miRNAs are more highly expressed in epithelial tumors than in B lymphoma [57]. BART transcription is regulated by its promoter regions, and P1 and P2 have been reported as BART promoters [58]. C/EBP $\alpha, \beta$, and $\delta$ have been shown to interact with $\mathrm{P} 2$, and the expression of the $\mathrm{C} / \mathrm{EBP} \beta$ protein was also detected in epithelial tumors but not in B lymphoma [58]. Moreover, the P2 region was shown to be highly methylated in type I latency B lymphoma in comparison to type III latency B lymphoma, and treatment with decitabine (5-Aza-2'-deoxycytidine; DAC) led to the recovery of the P2 promoter activity with the high expression of BART miRNA [59]. BART promoters may regulate BART transcription through a cell-type-specific transcription factor and epigenetic modification. 
Table 2. The role of miRNAs in EBVaGC.

\begin{tabular}{|c|c|c|c|c|}
\hline & miRNA & Target & Role of Targeted Gene & Reference \\
\hline \multirow{18}{*}{ EBV miRNAs } & \multirow{3}{*}{ miR-BART3 } & DICE1 & Apoptosis & [51] \\
\hline & & FEM1B & Apoptosis & [51] \\
\hline & & CASZ1a & Apoptosis & [51] \\
\hline & miR-BART4-5p & BID & Apoptosis & [50] \\
\hline & \multirow{3}{*}{ miR-BART6-5p } & DICER1 & Lytic replication-related genes & {$[51,54]$} \\
\hline & & DICER1 & Repressor of EMT & {$[51,60]$} \\
\hline & & OCT1 & Apoptosis & {$[46,51]$} \\
\hline & miR-BART8 & ARID2 & Tumor suppressor gene & [51] \\
\hline & miR-BART11 & FOXP1 & Cellular differentiation factor & [53] \\
\hline & \multirow{3}{*}{ miR-BART16 } & CREBBP & Apoptosis & [51] \\
\hline & & SH2B3 & Apoptosis & [51] \\
\hline & & TOMM22 & Mitochondrial transporter & [51] \\
\hline & \multirow{2}{*}{ miR-BART20-5p } & BAD & Apoptosis & [49] \\
\hline & & BZLF1/BRLF1 & Lytic replication-related genes & [49] \\
\hline & \multirow{4}{*}{ miR-BART22 } & PPP3R1 & Apoptosis & [51] \\
\hline & & PAK2 & Apoptosis & [51] \\
\hline & & TP53INP1 & Apoptosis & [51] \\
\hline & & NDRG1 & Cellular differentiation factor & [52] \\
\hline \multirow{3}{*}{ Host miRNA (Reduction) } & miR-200 & ZEB1, ZEB2 & Repressor of EMT & {$[61,62]$} \\
\hline & miR-143-3p & KLF4, ELK1 & Stem cell factor & {$[61,62]$} \\
\hline & miR-146b & STAT3 & Inflammation (IL-6) & {$[61,62]$} \\
\hline
\end{tabular}

EBVaGC: Epstein-Barr virus-associated gastric carcinoma; EMT: epithelial mesenchymal transition.

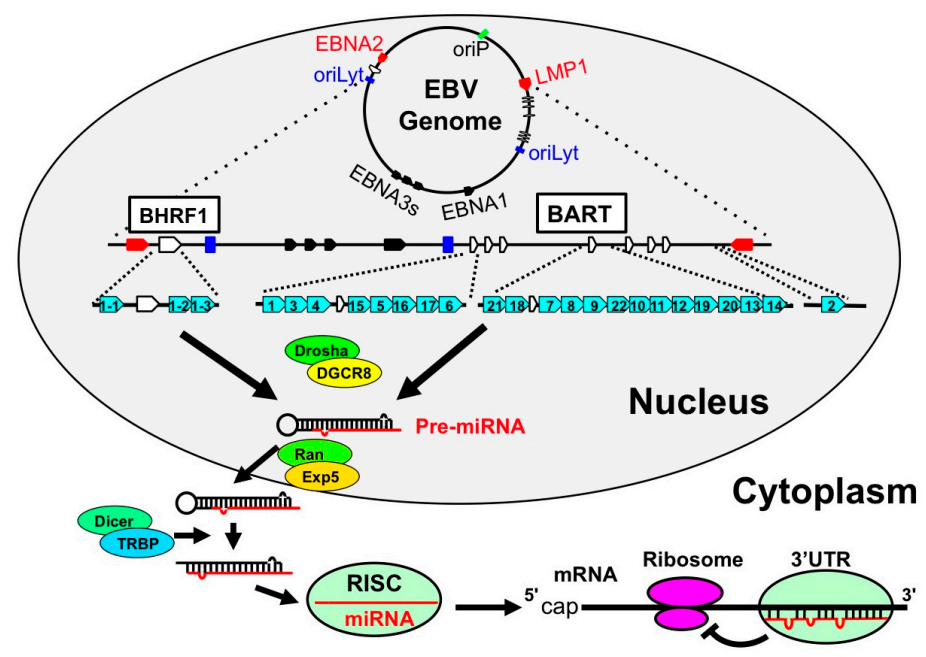

Figure 3. The genomic location of EBV-encoded miRNAs. In latently-infected cells, the EBV genome exists in the nucleus as a circular episome. The starting sites of viral replication are indicated as a green box (origin of plasmid replication; oriP) and blue boxes (origins of lytic replication; oriLyt). The coding regions of the latent membrane protein 1 (LMP1) and EBNA2 are indicated as red arrows. These are transcribed in antisense and sense orientations, respectively. EBNA3s and EBNA1 are indicated as black arrows. With regard to the BHRF miRNAs, BHRF1 ORF is encompassed with one $5^{\prime}$-end and two $3^{\prime}$-end miRNAs (light blue arrows). BART miRNAs are located in the intron region of noncoding RNA BART and are indicated as blue arrows. The white arrows indicate the BHRF and BART exons. (1) Drosha processing: pri-miRNAs are processed by Drosha-DGCR8 complex to become pre-miRNAs. (2) Pre-miRNA transport: pre-miRNAs are then transferred from the nucleus to the cytoplasm by Exportin5-RanGTP8 complex. (3) Dicer processing: pre-miRNAs are digested by Dicer-TRBP complex and miRNAs are generated. (4) RISC loading and translational inhibition: and miRNAs are incorporated into RNA-induced silencing complex (RISC) and specifically inhibit the translation of the targeted mRNA. 
These reports indicate that miR-BARTs have various roles, including the repression of apoptosis, the induction of dedifferentiation, and the maintenance of latent infection.

\subsection{Host miRNAs}

EBV derived microRNAs repress translation from viral and host mRNAs. Shinozaki et al. reported that EBV encoded EBNA1 and that LMP2A repressed the expression of pri-mir-200, which is a repressor of epithelial mesenchymal transition (EMT) [60]. In addition, Marquitz et al. analyzed the miRNA profile of AGS-EBV, an EBV experimentally-infected gastric carcinoma cell line, and reported that EBV infection reduced host expression levels of miR-200, miR-143-3p, and miR-146b [61]. The low expression of host miRNAs was reported to be associated with the prognosis of cancer [62]. Dicer is an essential factor in the generation of miRNAs, such as miR-200, and the low expression of Dicer enhances tumor metastasis via the induction of EMT [63]. EBV has been shown to encode miR-BART6 and to target Dicer [54]. These reports suggest that EBV infection changes the host miRNA profile and changes in this profile may enhance the metastatic activity of EBV-infected tumor cells.

\section{Long Non-Coding RNA (lncRNA)}

LncRNA is a long non-coding RNA of $\geq 200$ bases, and 27,919 lncRNAs have been identified in humans [64]. The function of lncRNA is largely unknown. However, lncRNAs bind to polycomb complex (PRC1 and PRC2) and inhibit transcription via histone modification (Figure 4A). Moreover, IncRNAs also interact with miRNAs (instead of protein-coding mRNAs) and enhance translation (Figure 4B) [65].

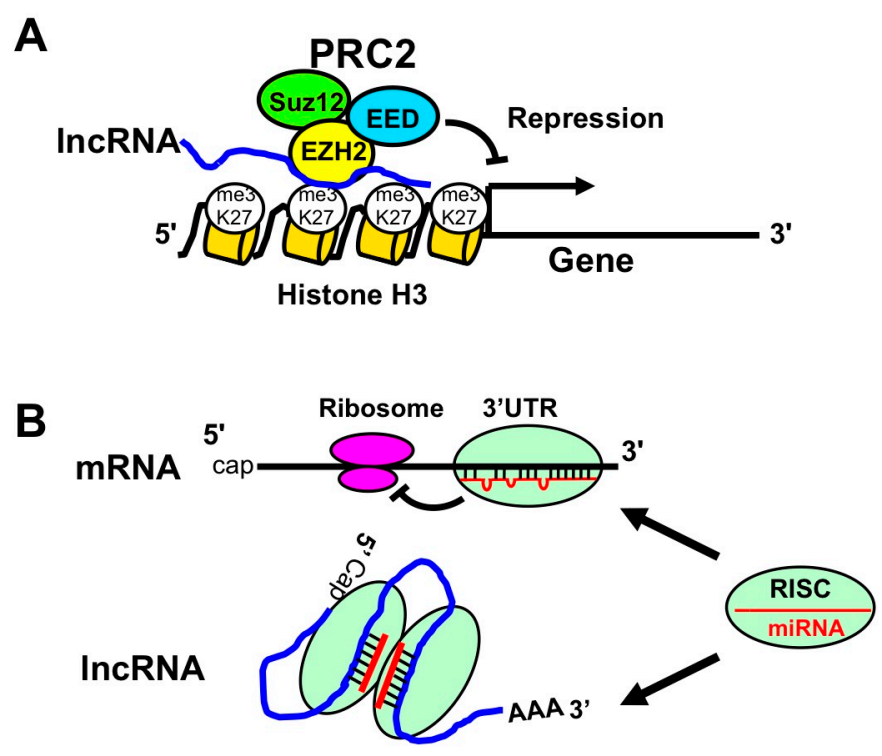

Figure 4. The role of long non-coding RNAs (lncRNAs). (A) LncRNA-PRC2 complex suppresses gene transcription. LncRNA binds to polycomb proteins, such as EZH2, EED, and Suz12. These proteins are recognized as PRC2. PRC2-lncRNA complex interacts with $\mathrm{K} 27$ of histone $\mathrm{H} 3$ and induces the trimethylation of $\mathrm{K} 27$ (me3K27). The resulting histone modification represses the transcription of targeted genes; (B) LncRNAs repress miRNA function by absorption of miRNA. The upper panel illustrates the well-known repression of translation by RISC-miRNA complex through its binding to $3^{\prime} \mathrm{UTR}$ of mRNA. The lower panel illustrates the interaction of lncRNA with miRNA via the targeting sequences. Since lncRNA absorbs miRNA, the association of miRNA with protein coding mRNAs will be decreased to increase the protein expression levels. 


\subsection{EBV Encoded lncRNAs}

EBV encodes viral miRNAs in the intron region of BART lncRNA [22]. However, BART IncRNA also regulates host mRNA expression. Recently, Marquitz et al. reported that BART IncRNA reduced the expression of amino acid transporter $\mathrm{xCT}$, cadherin superfamily $\mathrm{CDH} 11$, and $\mathrm{E} 3$ ubiquitin ligase RNF144B [66]. $\mathrm{xCT}$ is a glutamate-cystine transporter that is highly expressed in cancer stem cells to erase reactive oxygen species [67]. Moreover, RNF144B, which is one of the $\Delta$ Np63 downstream genes, enhances the degradation of p21 to induce cell proliferation [68]. These reports suggest that BART lncRNA may repress tumor malignancy in EBVaGC. It has also been reported that several lncRNAs expressed by oriP latently infected cells with EBV [69]. The role of BART lncRNA and these viral lncRNAs in tumor malignancy remains unclear.

\subsection{Host $\operatorname{lnc} R N A s$}

EBV infection alters the mRNA expression profile, including the expression of lncRNAs, in tumor cells. RNU12, H19, RP11-359D14.3, SNHG8, and MIR143HG were shown to be highly expressed in EBVaGC [70]. The expression of H19 induces the proliferation of gastric carcinoma cells [71]. Moreover, H19 is expressed not only in EBVaGC, but also in lymphoblastoma, suggesting that H19 may be associated with EBV-related tumors [72].

These reports indicate that EBV induces tumor malignancy by regulating the expression of non-coding RNA in gastric carcinoma. Recently, several review articles reported on miRNA and lncRNA in relation to EBV and gastric cancer [73-75]. For example, it was introduced that HOTAIR, GAS5, and MEG3 were highly expressed in gastric carcinoma [75]. However, it is unclear that the role of these lncRNAs in EBVaGC. To understand the role of non-coding RNA in EBVaGC, further studies are needed.

\section{Demethylating Agents in EBV-Associated Gastric Cancer}

DAC and azacitidine are DNA demethylating agents that have shown clinical efficacy in the treatment of hematological malignancies [76-78]. DAC prolongs the overall survival of patients with myelodysplastic syndrome and acute myeloid leukemia. Combination therapy with anti-cancer agents and DAC also improves the prognosis of acute lymphocytic leukemia $[79,80]$.

With regard to the clinical application of demethylating agents against EBVaGC, we investigated the effects of DAC against EBVaGC cell lines. DAC was found to induce G2/M arrest, apoptosis, and the expression of E-cadherin in SNU719 cells. The promoter regions of p73 and RUNX3 were demethylated, and their expression was upregulated by DAC treatment [81]. We also examined the effect of another demethylating agent, zebularine, and found that it inhibited the growth of SNU719 and NCC24 cells, which were derived from EBV-positive gastric adenocarcinoma [81].

It is known that DAC changes the expression of EBV genes that switch latent EBV infection to lytic EBV infection in infected cells [82-85]. BZLF1, a transcriptional activator that mediates the switch between the latent and the lytic forms of EBV infection, was found to be upregulated in SNU719 cells. The expression of BZLF1 causes apoptosis of the host cell and the release of EBV particles [86-89]. This upregulation of BZLF1 is considered to be one of the mechanisms underlying the anti-tumor effect of DAC in EBV-associated cancers. These facts strongly support the possible application of demethylating agents in the medical treatment of EBVaGC.

The efficacy of DAC in the treatment of solid tumors has not been reported [90]. Recently, a phase I study of 5-azacitidine prior to standard neoadjuvant chemotherapy was conducted for patients with gastric adenocarcinoma. Epigenetic priming with azacitidine plus chemotherapy was well-tolerated, and a multi-institutional phase II study is being developed using the established dose of azacytidine. Demethylating agents can be applied to the treatment of EBVaGC because promoter hypermethylation of the tumor suppressor gene is a key mechanism in the development of EBVaGC [22,91]. 


\section{Conclusions}

Methylation of both viral and host DNA is one of the major mechanisms involved in the development of EBVaGC. DNA methylation regulates the expression of miRNAs and IncRNAs coded in both viral and host DNA and is also involved in EBV-induced transformation of gastric cells. Epigenetic therapy could potentially be applied to the treatment of EBVaGC.

Acknowledgments: This study was supported in part by a Grant-in-Aid for Scientific Research from the Ministry of Education, Culture, Science and Technology of Japan (no. 26460938 and no.16H05843) to Jun Nishikawa and Hironori Yoshiyama, respectively.

Author Contributions: Jun Nishikawa, Hisashi Iizasa, and Hironori Yoshiyama conceived and wrote the article; Munetaka Nakamura, Mari Saito, Kouhei Sakai, and Yutaka Suehiro demonstrated genes specifically methylated in EBVaGCs; Sho Sasaki, Kanami Shimokuri, and Masashi Yanagihara studied effect of demethylating agents for EBVaGCs; Takahiro Yamasaki, and Isao Sakaida critically reviewed and gave their final approval of the article.

Conflicts of Interest: The authors declare no conflict of interest.

\section{References}

1. Ferlay, J.; Soerjomataram, I.; Dikshit, R.; Eser, S.; Mathers, C.; Rebelo, M.; Parkin, D.M.; Forman, D.; Bray, F. Cancer incidence and mortality worldwide: Sources, methods and major patterns in GLOBOCAN 2012. Int. J. Cancer 2015, 136, E359-E386. [CrossRef] [PubMed]

2. Bollschweiler, E.; Berlth, F.; Baltin, C.; Mönig, S.; Hölscher, A.H. Treatment of early gastric cancer in the Western World. World J. Gastroenterol. 2014, 20, 5672-5678. [CrossRef] [PubMed]

3. Piazuelo, M.B.; Epplein, M.; Correa, P. Gastric cancer: An infectious disease. Infect. Dis. Clin. N. Am. 2010, 24, 853-869. [CrossRef] [PubMed]

4. zur Hausen, H.; Schulte-Holthausen, H.; Klein, G.; Henle, W.; Henle, G.; Clifford, P.; Santesson, L. EBV DNA in biopsies of Burkitt tumours and anaplastic carcinomas of the nasopharynx. Nature 1970, 228, 1056-1058. [CrossRef] [PubMed]

5. Burke, A.P.; Yen, T.S.; Shekitka, K.M.; Sobin, L.H. Lymphoepithelial carcinoma of the stomach with Epstein-Barr virus demonstrated by polymerase chain reaction. Mod. Pathol. 1990, 3, 377-380. [PubMed]

6. Takada, K. Epstein-Barr virus and gastric carcinoma. Mol. Pathol. 2000, 53, 255-261. [CrossRef] [PubMed]

7. Shibata, D.; Weiss, L.M. Epstein-Barr virus-associated gastric adenocarcinoma. Am. J. Pathol. 1992, 140, 769-774. [PubMed]

8. Tokunaga, M.; Land, C.E.; Uemura, Y.; Tokudome, T.; Tanaka, S.; Sato, E. Epstein-Barr virus in gastric carcinoma. Am. J. Pathol. 1993, 143, 1250-1254. [PubMed]

9. Imai, S.; Koizumi, S.; Sugiura, M.; Tokunaga, M.; Uemura, Y.; Yamamoto, N.; Tanaka, S.; Sato, E.; Osato, T. Gastric carcinoma: Monoclonal epithelial malignant cells expressing Epstein-Barr virus latent infection protein. Proc. Natl. Acad. Sci. USA 1994, 91, 9131-9135. [CrossRef] [PubMed]

10. Fukayama, M.; Hayashi, Y.; Iwasaki, Y.; Chong, J.; Ooba, T.; Takizawa, T.; Koike, M.; Mizutani, S.; Miyaki, M.; Hirai, K. Epstein-Barr virus-associated gastric carcinoma and Epstein-Barr virus infection of the stomach. Lab. Investig. 1994, 71, 73-81. [PubMed]

11. The Cancer Genome Atlas Research Network. Comprehensive molecular characterization of gastric adenocarcinoma. Nature 2014, 513, 202-209.

12. Kawazoe, A.; Kuwata, T.; Kuboki, Y.; Shitara, K.; Nagatsuma, A.K.; Aizawa, M.; Yoshino, T.; Doi, T.; Ohtsu, A.; Ochiai, A. Clinicopathological features of programmed death ligand 1 expression with tumor-infiltrating lymphocyte, mismatch repair, and Epstein-Barr virus status in a large cohort of gastric cancer patients. Gastric Cancer 2017, 20, 407-415. [CrossRef] [PubMed]

13. Derks, S.; Liao, X.; Chiaravalli, A.M.; Xu, X.; Camargo, M.C.; Solcia, E.; Sessa, F.; Fleitas, T.; Freeman, G.J.; Rodig, S.J.; et al. Abundant PD-L1 expression in Epstein-Barr Virus-infected gastric cancers. Oncotarget 2016, 7, 32925-32932. [CrossRef] [PubMed]

14. Ma, C.; Patel, K.; Singhi, A.D.; Ren, B.; Zhu, B.; Shaikh, F.; Sun, W. Programmed death-ligand 1 expression is common in gastric cancer associated with Epstein-Barr virus or microsatellite instability. Am. J. Surg. Pathol. 2016, 40, 1496-1506. [CrossRef] [PubMed] 
15. Chang, M.S.; Uozaki, H.; Chong, J.M.; Ushiku, T.; Sakuma, K.; Ishikawa, S.; Hino, R.; Barua, R.R.; Iwasaki, Y.; Arai, K.; et al. CpG island methylation status in gastric carcinoma with and without infection of Epstein-Barr virus. Clin. Cancer Res. 2006, 12, 2995-3002. [PubMed]

16. Kusano, M.; Toyota, M.; Suzuki, H.; Akino, K.; Aoki, F.; Fujita, M.; Hosokawa, M.; Shinomura, Y.; Imai, K.; Tokino, T. Genetic, epigenetic, and clinicopathologic features of gastric carcinomas with the CpG island methylator phenotype and an association with Epstein-Barr virus. Cancer 2006, 106, 1467-1479. [CrossRef] [PubMed]

17. Kaneda, A.; Matsusaka, K.; Aburatani, H.; Fukayama, M. Epstein-Barr virus infection as an epigenetic driver of tumorigenesis. Cancer Res. 2012, 72, 3445-3450. [CrossRef] [PubMed]

18. Okada, T.; Nakamura, M.; Nishikawa, J.; Sakai, K.; Zhang, Y.; Saito, M.; Morishige, A.; Oga, A.; Sasaki, K.; Suehiro, Y.; et al. Identification of genes specifically methylated in Epstein-Barr virus-associated gastric carcinomas. Cancer Sci. 2013, 104, 1309-1314. [CrossRef] [PubMed]

19. Saito, M.; Nishikawa, J.; Okada, T.; Morishige, A.; Sakai, K.; Nakamura, M.; Kiyotoki, S.; Hamabe, K.; Okamoto, T.; Oga, A.; et al. Role of DNA methylation in the development of Epstein-Barr virus-associated gastric carcinoma. J. Med. Virol. 2013, 85, 121-127. [CrossRef] [PubMed]

20. Niller, H.H.; Wolf, H.; Minarovits, J. Epigenetic dysregulation of the host cell genome in Epstein-Barr virus-associated neoplasia. Semin. Cancer Biol. 2009, 19, 158-164. [CrossRef] [PubMed]

21. Ernberg, I.; Falk, K.; Minarovits, J.; Busson, P.; Tursz, T.; Masucci, M.G.; Klein, G. The role of methylation in the phenotype-dependent modulation of Epstein-Barr nuclear antigen 2 and latent membrane protein genes in cells latently infected with Epstein-Barr virus. J. Gen. Virol. 1989, 70, 2989-3002. [CrossRef] [PubMed]

22. Masucci, M.G.; Contreras-Salazar, B.; Ragnar, E.; Falk, K.; Minarovits, J.; Ernberg, I.; Klein, G. 5-Azacytidine up regulates the expression of Epstein-Barr virus nuclear antigen 2 (EBNA-2) through EBNA-6 and latent membrane protein in the Burkitt's lymphoma line rael. J. Virol. 1989, 63, 3135-3141. [PubMed]

23. Sugiura, M.; Imai, S.; Tokunaga, M.; Koizumi, S.; Uchizawa, M.; Okamoto, K.; Osato, T. Transcriptional analysis of Epstein-Barr virus gene expression in EBV-positive gastric carcinoma: Unique viral latency in the tumour cells. Br. J. Cancer 1996, 74, 625-631. [CrossRef] [PubMed]

24. Luo, B.; Wang, Y.; Wang, X.F.; Liang, H.; Yan, L.P.; Huang, B.H.; Zhao, P. Expression of Epstein-Barr virus genes in EBV-associated gastric carcinomas. World J. Gastroenterol. 2005, 11, 629-633. [CrossRef] [PubMed]

25. Tang, W.; Morgan, D.R.; Meyers, M.O.; Dominguez, R.L.; Martinez, E.; Kakudo, K.; Kuan, P.F.; Banet, N.; Muallem, H.; Woodward, K.; et al. Epstein-barr virus infected gastric adenocarcinoma expresses latent and lytic viral transcripts and has a distinct human gene expression profile. Infect. Agent Cancer 2012, 7, 21. [CrossRef] [PubMed]

26. Strong, M.J.; Laskow, T.; Nakhoul, H.; Blanchard, E.; Liu, Y.; Wang, X.; Baddoo, M.; Lin, Z.; Yin, Q.; Flemington, E.K. Latent expression of the Epstein-Barr virus (EBV)-encoded major histocompatibility complex class I TAP inhibitor, BNLF2a, in EBV-positive gastric carcinomas. J. Virol. 2015, 89, 10110-10114. [CrossRef] [PubMed]

27. Ribeiro, J.; Oliveira, C.; Malta, M.; Sousa, H. Epstein-Barr virus gene expression and latency pattern in gastric carcinomas: A systematic review. Future Oncol. 2017, 13, 567-579. [CrossRef] [PubMed]

28. Hu, L.F.; Minarovits, J.; Cao, S.L.; Contreras-Salazar, B.; Rymo, L.; Falk, K.; Klein, G.; Ernberg, I. Variable expression of latent membrane protein in nasopharyngeal carcinoma can be related to methylation status of the Epstein-Barr virus BNLF-1 5'-flanking region. J. Virol. 1991, 65, 1558-1567. [PubMed]

29. Iizasa, H.; Nanbo, A.; Nishikawa, J.; Jinushi, M.; Yoshiyama, H. Epstein-Barr Virus (EBV)-associated gastric carcinoma. Viruses 2012, 4, 3420-3439. [CrossRef] [PubMed]

30. Nishikawa, J.; Yoshiyama, H.; Iizasa, H.; Kanehiro, Y.; Nakamura, M.; Nishimura, J.; Saito, M.; Okamoto, T.; Sakai, K.; Suehiro, Y.; et al. Epstein-barr virus in gastric carcinoma. Cancers 2014, 6, 2259-2274. [CrossRef] [PubMed]

31. Kang, G.H.; Lee, S.; Kim, W.H.; Lee, H.W.; Kim, J.C.; Rhyu, M.G.; Ro, J.Y. Epstein-barr virus-positive gastric carcinoma demonstrates frequent aberrant methylation of multiple genes and constitutes $\mathrm{CpG}$ island methylator phenotype-positive gastric carcinoma. Am. J. Pathol. 2002, 160, 787-794. [CrossRef]

32. Vo, Q.N.; Geradts, J.; Gulley, M.L.; Boudreau, D.A.; Bravo, J.C.; Schneider, B.G. Epstein-Barr virus in gastric adenocarcinomas: Association with ethnicity and CDKN2A promoter methylation. J. Clin. Pathol. 2002, 55, 669-675. [CrossRef] [PubMed] 
33. Chong, J.M.; Sakuma, K.; Sudo, M.; Ushiku, T.; Uozaki, H.; Shibahara, J.; Nagai, H.; Funata, N.; Taniguchi, H.; Aburatani, H.; et al. Global and non-random CpG-island methylation in gastric carcinoma associated with Epstein-Barr virus. Cancer Sci. 2003, 94, 76-80. [CrossRef] [PubMed]

34. Dong, S.M.; Lee, H.G.; Cho, S.G.; Kwon, S.H.; Yoon, H.; Kwon, H.J.; Lee, J.H.; Kim, H.; Park, P.G.; Kim, H.; et al. Hypermethylation of the interferon regulatory factor 5 promoter in Epstein-Barr virus-associated gastric carcinoma. J. Microbiol. 2015, 53, 70-76. [CrossRef] [PubMed]

35. Yu, J.; Liang, Q.; Wang, J.; Wang, K.; Gao, J.; Zhang, J.; Zeng, Y.; Chiu, P.W.; Ng, E.K.; Sung, J.J. REC8 functions as a tumor suppressor and is epigenetically downregulated in gastric cancer, especially in EBV-positive subtype. Oncogene 2017, 36, 182-193. [CrossRef] [PubMed]

36. Kim, M.; Kim, J.H.; Baek, S.J.; Kim, S.Y.; Kim, Y.S. Specific expression and methylation of SLIT1, SLIT2, SLIT3, and miR-218 in gastric cancer subtypes. Int. J. Oncol. 2016, 48, 2497-2507. [CrossRef] [PubMed]

37. Hino, R.; Uozaki, H.; Murakami, N.; Ushiku, T.; Shinozaki, A.; Ishikawa, S.; Morikawa, T.; Nakaya, T.; Sakatani, T.; Takada, K.; et al. Activation of DNA methyltransferase 1 by EBV latent membrane protein 2A leads to promoter hypermethylation of PTEN gene in gastric carcinoma. Cancer Res. 2009, 69, 2766-2774. [CrossRef] [PubMed]

38. Lennette, E.T.; Winberg, G.; Yadav, M.; Enblad, G.; Klein, G. Antibodies to LMP2A/2B in EBV-carrying malignancies. Eur. J. Cancer 1995, 31A, 1875-1878. [CrossRef]

39. Tsai, C.L.; Li, H.P.; Lu, Y.J.; Hsueh, C.; Liang, Y.; Chen, C.L.; Tsao, S.W.; Tse, K.P.; Yu, J.S.; Chang, Y.S. Activation of DNA methyltransferase1 by EBV LMP1 Involves c-Jun NH(2)-terminal kinase signaling. Cancer Res. 2006, 66, 11668-11676. [CrossRef] [PubMed]

40. Tsai, C.N.; Tsai, C.L.; Tse, K.P.; Chang, H.Y.; Chang, Y.S. The Epstein-Barr virus oncogene product, latent membrane protein 1, induces the downregulation of E-cadherin gene expression via activation of DNA methyltransferases. Proc. Natl. Acad. Sci. USA 2002, 99, 10084-10089. [CrossRef] [PubMed]

41. Kida, Y.; Miyauchi, K.; Takano, Y. Gastric adenocarcinoma with differentiation to sarcomatous components associated with monoclonal Epstein-Barr virus infection and LMP-1 expression. Virchows Arch. A Pathol. Anat. Histopathol. 1993, 423, 383-387. [CrossRef] [PubMed]

42. Matsusaka, K.; Kaneda, A.; Nagae, G.; Ushiku, T.; Kikuchi, Y.; Hino, R.; Uozaki, H.; Seto, Y.; Takada, K.; Aburatani, H.; et al. Classification of Epstein-Barr virus-positive gastric cancers by definition of DNA methylation epigenotypes. Cancer Res. 2011, 71, 7187-7197. [CrossRef] [PubMed]

43. Matsusaka, K.; Funata, S.; Fukuyo, M.; Seto, Y.; Aburatani, H.; Fukayama, M.; Kaneda, A. Epstein-Barr virus infection induces genome-wide de novo DNA methylation in non-neoplastic gastric epithelial cells. J. Pathol. 2017. [CrossRef] [PubMed]

44. Wu, L.; Fan, J.; Belasco, J.G. MicroRNA direct rapid MicroRNAs direct rapid deadenylation of mRNA. Proc. Natl. Acad. Sci. USA 2006, 103, 4034-4039. [CrossRef] [PubMed]

45. Alexiou, P.; Maragkakis, M.; Papadopoulos, G.L.; Reczko, M.; Hatzigeorgiou, A.G. Lost in translation: An assessment and perspective for computational microRNA target identification. Bioinformatics 2009, 25, 3049-3055.

46. Pfeffer, S.; Zavolan, M.; Grasser, F.A.; Chien, M.; Russo, J.J.; John, B.; Enright, A.J.; Sander, C.; Tuschl, T. Identification of virus-encoded microRNAs. Science 2004, 304, 734-736. [CrossRef] [PubMed]

47. Cai, X.; Schater, A.; Lu, S.; Bilello, J.P.; Desrosiers, R.C.; Edwards, R.; Raab-Traub, N.; Cullen, B.R. Epstein-Barr virus microRNAs are evolutionarily conserved and differentially expressed. PLoS Pathog. 2006, 2, e23. [CrossRef] [PubMed]

48. Qiu, J.; Cosmopoulos, K.; Pegtel, M.; Hopmans, E.; Murray, P.; Middeldorp, J.; Shapiro, M.; Thorley-Lawson, D.A. A novel persistence associated EBV miRNA expression profile is distributed in neoplasia. PLoS Pathog. 2011, 7, e1002193. [CrossRef] [PubMed]

49. Kim, H.; Choi, H.; Lee, S.K. Epstein-Barr virus miR-BART20-5p regulates cell proliferation and apoptosis by targeting BAD. Cancer Lett. 2015, 356, 733-742. [CrossRef] [PubMed]

50. Shinozaki-Ushiku, A.; Kunita, A.; Isogai, M.; Hibiya, T.; Ushiku, T.; Takada, K.; Fukayama, M. Profiling of Virus-Encoded MicroRNAs in Epstein-Barr Virus-Associated Gastric Carcinoma and Their Roles in Gastric Carcinogenesis. J. Virol. 2015, 89, 5581-5591. [CrossRef] [PubMed]

51. Kang, D.; Skalsky, R.L.; Cullen, B.R. EBV BART microRNAs target multiple pro-apoptotic cellular genes to promote epithelial cell survival. PLoS Pathog. 2015, 11, e1004979. [CrossRef] [PubMed] 
52. Kanda, T.; Miyata, M.; Kano, M.; Kondo, S.; Yoshizaki, T.; Iizasa, H. Clustered microRNAs of the Epstein-Barr virus cooperatively downregulate an epithelial cell-specific metastasis suppressor. J. Virol. 2015, 89, 2684-2697. [CrossRef] [PubMed]

53. Song, Y.; Li, X.; Zeng, Z.; Li, Q.; Gong, Z.; Liao, Q.; Li, X.; Chen, P.; Xiang, B.; Zhang, W.; et al. Epstein-Barr virus encoded miR-BART11 promotes inflammation-induced carcinogenesis by targeting FOXP1. Oncotarget 2016, 7, 36783-36799. [CrossRef] [PubMed]

54. Iizasa, H.; Wulff, B.E.; Alla, N.R.; Maragkakis, M.; Megraw, M.; Hatzigeorgiou, A.; Iwakiri, D.; Takada, K.; Wiedmer, A.; Showe, L.; et al. Editing of Epstein-Barr virus-encoded BART6 microRNAs controls their dicer targeting and consequently affects viral latency. J. Biol. Chem. 2010, 285, 33358-33370. [CrossRef] [PubMed]

55. Jung, Y.J.; Choi, H.; Kim, H.; Lee, S.K. MicroRNA miR-BART20-5p stabilizes Epstein-Barr virus latency by directly targeting BZLF1 and BRLF1. J. Virol. 2014, 88, 9027-9037. [CrossRef] [PubMed]

56. Lin, X.; Tsai, M.H.; Shumilov, A.; Poirey, R.; Bannert, H.; Middeldorp, J.M.; Feederle, R.; Delecluse, H.J. The Epstein-Barr virus BART miRNA cluster of the M81 strain modulates multiple functions in primary B cells. PLoS Pathog. 2015, 11, e1005344. [CrossRef] [PubMed]

57. Chen, S.J.; Chen, G.H.; Chen, Y.H.; Liu, C.Y.; Chang, K.P.; Chang, Y.S.; Chen, H.C. Characterization of Epstein-Barr virus miRNAome in nasopharyngeal carcinoma by deep sequencing. PLoS ONE 2010, 5, e12745. [CrossRef] [PubMed]

58. Chen, H.; Huang, J.; Wu, F.Y.; Liao, G.; Hutt-Fletcher, L.; Hayward, S.D. Regulation of expression of the Epstein-Barr virus BamHI-A rightward transcripts. J. Virol. 2005, 79, 1724-1733. [CrossRef] [PubMed]

59. Kim, D.N.; Song, Y.J.; Lee, S.K. The role of promoter methylation in Epstein-Barr virus (EBV) microRNA expression in EBV-infected B cell lines. Exp. Mol. Med. 2011, 43, 401-410. [CrossRef] [PubMed]

60. Shinozaki, A.; Sakatani, T.; Ushiku, T.; Hino, R.; Isogai, M.; Ishikawa, S.; Uozaki, H.; Takada, K.; Fukayama, M. Downregulation of microRNA-200 in EBV-associated gastric carcinoma. Cancer Res. 2010, 70, 4719-4727. [CrossRef] [PubMed]

61. Marquitz, A.R.; Mathur, A.; Chugh, P.E.; Dittmer, D.P.; Raab-Traub, N. Expression profile of microRNAs in Epstein-Barr virus-infected AGS gastric carcinoma cells. J. Virol. 2014, 88, 1389-1393. [CrossRef] [PubMed]

62. Martello, G.; Rosato, A.; Ferrari, F.; Manfrin, A.; Cordenonsi, M.; Dupont, S.; Enzo, E.; Guzzardo, V.; Rondina, M.; Spruce, T.; et al. MicroRNA targeting dicer for metastasis control. Cell 2010, 141, 1195-1207. [CrossRef] [PubMed]

63. Merritt, W.M.; Lin, Y.G.; Han, L.Y.; Kamat, A.A.; Spannuth, W.A.; Schmandt, R.; Urbauer, D.; Pennacchio, L.A.; Cheng, J.F.; Nick, A.M.; et al. Dicer, Drosha, and outcomes in patients with ovarian cancer. N. Engl. J. Med. 2008, 359, 2641-2650. [CrossRef] [PubMed]

64. Hon, C.C.; Ramilowski, J.A.; Harshbarger, J.; Bertin, N.; Rackham, O.J.; Gough, J.; Denisenko, E.; Schmeier, S.; Poulsen, T.M.; Severin, J.; et al. An atlas of human long non-coding RNAs with accurate $5^{\prime}$ ends. Nature 2017, 543, 199-204. [CrossRef] [PubMed]

65. Quinn, J.J.; Chang, H.Y. Unique features of long non-coding RNA biogenesis and function. Nat. Rev. Genet. 2016, 17, 47-62. [CrossRef] [PubMed]

66. Marquitz, A.R.; Mathur, A.; Edwards, R.H.; Raab-Traub, N. Host Gene Expression Is Regulated by Two Types of Noncoding RNAs Transcribed from the Epstein-Barr Virus BamHI A Rightward Transcript Region. J. Virol. 2015, 89, 11256-11268. [CrossRef] [PubMed]

67. Ishimoto, T.; Nagano, O.; Yae, T.; Tamada, M.; Motohara, T.; Oshima, H.; Oshima, M.; Ikeda, T.; Asaba, R.; Yagi, H.; et al. CD44 variant regulates redox status in cancer cells by stabilizing the XCT subunit of system xc- and thereby promotes tumor growth. Cancer Cell 2011, 19, 387-400. [CrossRef] [PubMed]

68. Conforti, F.; Yang, A.L.; Piro, M.C.; Mellone, M.; Terrinoni, A.; Candi, E.; Tucci, P.; Thomas, G.J.; Knight, R.A.; Melino, G.; et al. PIR2/Rnf144B regulates epithelial homeostasis by mediating degradation of p21WAF1 and p63. Oncogene 2013, 32, 4758-4765. [CrossRef] [PubMed]

69. Cao, S.; Moss, W.; O'Grady, T.; Concha, M.; Strong, M.J.; Wang, X.; Yu, Y.; Baddoo, M.; Zhang, K.; Fewell, C.; et al. New noncoding lytic transcripts derived from the Epstein-Barr Virus Latency Origin of Replication, oriP, are hyperedited, bind the paraspeckle protein, NONO/p54nrb, and support viral lytic transcription. J. Virol. 2015, 89, 7120-7132. [CrossRef] [PubMed]

70. Huang, T.; Ji, Y.; Hu, D.; Chen, B.; Zhang, H.; Li, C.; Chen, G.; Luo, X.; Zheng, X.W.; Lin, X. SNHG8 is identified as a key regulator of epstein-barr virus (EBV)-associated gastric cancer by an integrative analysis of lncRNA and mRNA expression. Oncotarget 2016, 7, 80990-81002. [CrossRef] [PubMed] 
71. Yang, F.; Bi, J.; Xue, X.; Zheng, L.; Zhi, K.; Hua, J.; Fang, G. Up-regulated long non-coding RNA H19 contributes to proliferation of gastric cancer cells. FEBS J. 2012, 279, 3159-3165. [CrossRef] [PubMed]

72. Gallo, A.; Vella, S.; Miele, M.; Timoneri, F.; Di Bella, M.; Bosi, S.; Sciveres, M.; Conaldi, P.G. Global profiling of viral and cellular non-coding RNAs in Epstein-Barr virus-induced lymphoblastoid cell lines and released exosome cargos. Cancer Lett. 2017, 388, 334-343. [CrossRef] [PubMed]

73. Piedade, D.; Azevedo-Pereira, J.M. The role of microRNAs in the pathogenesis of herpesvirus infection. Viruses 2016, 8, 156. [CrossRef]

74. Giudice, A.; D’Arena, G.; Crispo, A.; Tecce, M.F.; Nocerino, F.; Grimaldi, M.; Rotondo, E.; D'Ursi, A.M.; Scrima, M.; Galdiero, M.; et al. Role of viral miRNAs and epigenetic modifications in Epstein-Barr virus-associated gastric carcinogenesis. Oxid. Med. Cell. Longev. 2016, 2016, 6021934. [CrossRef] [PubMed]

75. Liu, X.; Meltzer, S.J. Gastric cancer in the era of precision medicine. Cell. Mol. Gastroenterol. Hepatol. 2017, 3 , 348-358. [CrossRef] [PubMed]

76. Silverman, L.R.; Demakos, E.P.; Peterson, B.L.; Kornblith, A.B.; Holland, J.C.; Odchimar-Reissig, R.; Stone, R.M.; Nelson, D.; Powell, B.L.; DeCastro, C.M.; et al. Randomized controlled trial of azacitidine in patients with the myelodysplastic syndrome: A study of the cancer and leukemia group B. J. Clin. Oncol. 2002, 20, 2429-2440. [CrossRef] [PubMed]

77. Kantarjian, H.; Issa, J.P.; Rosenfeld, C.S.; Bennett, J.M.; Albitar, M.; DiPersio, J.; Klimek, V.; Slack, J.; de Castro, C.; Ravandi, F.; et al. Decitabine improves patient outcomes in myelodysplastic syndromes: Results of a phase III randomized study. Cancer 2006, 106, 1794-1803. [CrossRef] [PubMed]

78. Fenaux, P.; Mufti, G.J.; Hellstrom-Lindberg, E.; Santini, V.; Finelli, C.; Giagounidis, A.; Schoch, R.; Gattermann, N.; Sanz, G.; List, A.; et al. Efficacy of azacitidine compared with that of conventional care regimens in the treatment of higher-risk myelodysplastic syndromes: A randomised, open-label, phase III study. Lancet Oncol. 2009, 10, 223-232. [CrossRef]

79. Benton, C.B.; Thomas, D.A.; Yang, H.; Ravandi, F.; Rytting, M.; O’Brien, S.; Franklin, A.R.; Borthakur, G.; Dara, S.; Kwari, M.; et al. Safety and clinical activity of 5-aza-2'-deoxycytidine (decitabine) with or without Hyper-CVAD in relapsed/refractory acute lymphocytic leukaemia. Br. J. Haematol. 2014, 167, $356-365$. [CrossRef]

80. Mayer, J.; Arthur, C.; Delaunay, J.; Mazur, G.; Thomas, X.G.; Wierzbowska, A.; Ravandi, F.; Berrak, E.; Jones, M.; Li, Y.; et al. Multivariate and subgroup analyses of a randomized, multinational, phase 3 trial of decitabine vs treatment choice of supportive care or cytarabine in older patients with newly diagnosed acute myeloid leukemia and poor- or intermediate-risk cytogenetics. BMC Cancer 2014, 14, 69. [CrossRef] [PubMed]

81. Nakamura, M.; Nishikawa, J.; Saito, M.; Sakai, K.; Sasaki, S.; Hashimoto, S.; Okamoto, T.; Suehiro, Y.; Yamasaki, T.; Sakaida, I. Decitabine inhibits tumor cell proliferation and up-regulates e-cadherin expression in Epstein-Barr virus-associated gastric cancer. J. Med. Virol. 2017, 89, 508-517. [CrossRef] [PubMed]

82. Rao, S.P.; Rechsteiner, M.P.; Berger, C.; Sigrist, J.A.; Nadal, D.; Bernasconi, M. Zebularine reactivates silenced E-cadherin but unlike 5-Azacytidine does not induce switching from latent to lytic Epstein-Barr virus infection in Burkitt's lymphoma Akata cells. Mol. Cancer 2007, 6, 3. [CrossRef] [PubMed]

83. Ye, J.; Gradoville, L.; Daigle, D.; Miller, G. De novo protein synthesis is required for lytic cycle reactivation of Epstein-Barr virus, but not Kaposi's sarcoma-associated herpesvirus, in response to histone deacetylase inhibitors and protein kinase C agonists. J. Virol. 2007, 81, 9279-9291. [CrossRef] [PubMed]

84. Countryman, J.K.; Gradoville, L.; Miller, G. Histone hyperacetylation occurs on promoters of lytic cycle regulatory genes in Epstein-Barr virus-infected cell lines which are refractory to disruption of latency by histone deacetylase inhibitors. J. Virol. 2008, 82, 4706-4719. [CrossRef] [PubMed]

85. Countryman, J.; Gradoville, L.; Bhaduri-McIntosh, S.; Ye, J.; Heston, L.; Himmelfarb, S.; Shedd, D.; Miller, G. Stimulus duration and response time independently influence the kinetics of lytic cycle reactivation of Epstein-Barr virus. J. Virol. 2009, 83, 10694-10709. [CrossRef] [PubMed]

86. Larochelle, B.; Flamand, L.; Gourde, P.; Beauchamp, D.; Gosselin, J. Epstein-Barr virus infects and induces apoptosis in human neutrophils. Blood 1998, 92, 291-299. [PubMed]

87. Inman, G.J.; Binné, U.K.; Parker, G.A.; Farrell, P.J.; Allday, M.J. Activators of the Epstein-Barr virus lytic program concomitantly induce apoptosis, but lytic gene expression protects from cell death. J. Virol. 2001, 75, 2400-2410. [CrossRef] [PubMed] 
88. Isobe, Y.; Sugimoto, K.; Yang, L.; Tamayose, K.; Egashira, M.; Kaneko, T.; Takada, K.; Oshimi, K. Epstein-Barr virus infection of human natural killer cell lines and peripheral blood natural killer cells. Cancer Res. 2004, 64, 2167-2174. [CrossRef] [PubMed]

89. Oussaief, L.; Hippocrate, A.; Clybouw, C.; Rampanou, A.; Ramirez, V.; Desgranges, C.; Vazquez, A.; Khelifa, R.; Joab, I. Activation of the lytic program of the Epstein-Barr virus in Burkitt's lymphoma cells leads to a two steps downregulation of expression of the proapoptotic protein BimEL, one of which is EBV-late-gene expression dependent. Virology 2009, 387, 41-49. [CrossRef] [PubMed]

90. Fang, F.; Zuo, Q.; Pilrose, J.; Wang, Y.; Shen, C.; Li, M.; Wulfridge, P.; Matei, D.; Nephew, K.P. Decitabine reactivated pathways in platinum resistant ovarian cancer. Oncotarget 2014, 5, 3579-3589. [CrossRef] [PubMed]

91. Fukayama, F.; Ushiku, T. Epstein-Barr virus-associated gastric carcinoma. Pathol. Res. Pract. 2011, 207, 529-537. [CrossRef] [PubMed]

(C) 2017 by the authors. Licensee MDPI, Basel, Switzerland. This article is an open access article distributed under the terms and conditions of the Creative Commons Attribution (CC BY) license (http://creativecommons.org/licenses/by/4.0/). 